\title{
The involvement in childcare of married and cohabiting fathers: evidence from Italy

\author{
Silvia Meggiolaro *i] and Fausta Ongaro
}

\author{
* Correspondence: meg@stat.unipd. \\ Department of Statistical Sciences, \\ University of Padova, Via Cesare \\ Battisti, 24135121 Padova, Italy
}

\begin{abstract}
This study analyses paternal involvement in the daily basic childcare of Italian cohabiting and married fathers with children aged $0-3$. The aims are (a) to verify whether cohabiting fathers are more or less involved in childcare than married ones are and (b) to examine the mechanisms behind the possible differences. The focus is on both the daily basic childcare as a whole and on the specific activities of daily basic care (such as putting the child to sleep, dressing the child and changing its nappies). In addition, also potential differences among married fathers are examined, distinguishing between those who marry directly and those with pre-marital cohabitation. Results show that a higher involvement in the daily basic childcare of cohabiting fathers and of married fathers with pre-marital cohabitation may be completely explained by the fact that these typologies of couples are selected by structural differences which are positively associated with the higher fathers' basic childcare.

Keywords: Childcare, Fatherhood, Cohabitation, Italy
\end{abstract}

\section{Introduction}

Since the literature has stressed the relevance for the children's development and wellbeing of an active involvement of the father in the childcare (Pleck and Masciadrelli 2004; Pleck 2010; Smith Leavell et al. 2012), research has become increasingly focused on this topic. However, most of these studies have referred to married or to non-resident fathers. Little is known about the paternal involvement in childcare of unwed resident fathers (González et al. 2010; Perry et al. 2012; Bianchi et al. 2014), despite the fact that cohabitation is rapidly increasing in western societies (Kasearu and Kutsar 2011).

This study aims to fill, at least partly, this gap in the literature by analysing paternal involvement in the daily basic childcare (such as feeding the child, putting it to sleep or changing its nappies) performed by Italian cohabiting and married fathers with children aged 0-3. Are cohabiting fathers more or less involved in childcare than married ones are? If so, what are the mechanisms behind these (possible) differences? Is there a direct causal relationship between marital status and the paternal role or rather an indirect effect due to certain structural differences such as the father's or familial characteristics? We will focus on answering these questions for both a group of daily basic care as a whole and, more specifically, for each type of basic care performed within Italian families.

(c) The Author(s). 2019 Open Access This article is distributed under the terms of the Creative Commons Attribution 4.0 International License (http://creativecommons.org/licenses/by/4.0/), which permits unrestricted use, distribution, and reproduction in any medium, provided you give appropriate credit to the original author(s) and the source, provide a link to the Creative Commons license, and indicate if changes were made. 
If married and cohabiting fathers differ in terms of their involvement in childcare, the diffusion of non-marital unions could have important consequences for children, since the role of paternal involvement in children's development is crucial (Aldous and Mulligan 2002; Bronte-Tinkew et al. 2008). Activities connected with daily basic childcare are obviously not exhaustive of the multiple dimensions of paternal involvement (engagement, accessibility, responsibility, ${ }^{1}$ see Lamb et al. 1987 and Lamb 2000) and are not even exhaustive of all the direct father-child interactions examined through the engagement component. However, for babies aged 0-3 years, they account for a large part of the children's needs and are of the upmost importance in terms of the development of warm and rich father-child relationships. Moreover, the father's involvement in these activities, which are traditionally attributed to the mother, is assumed to ease the mother's workload.

This topic is of particular interest in a context such as Italy. Even if occurring later than in other European regions (Kiernan 2002), non-marital unions have become increasingly common also in this country (Salvini and De Rose 2011). As a consequence, out-of-wedlock births have dramatically increased, passing from 8.9\% in 1997 to $24.8 \%$ in 2012 (Italian Statistical Yearbook 2001, 2015). However, the percentage remains lower compared to many other European countries. For example, in 2012, the percentage of out-of-wedlock births is higher than $40 \%$ in countries such as Belgium and the Netherlands, and even higher than $50 \%$ in countries such as Sweden, Norway, and France (Eurostat Demographic Statistics ${ }^{2}$ ). The fact that cohabitation is less common is often associated both with lower social acceptance and less legal acknowledgement of cohabitation (and this, indeed, is the case in $I$ taly ${ }^{3}$ ). Thus, we cannot exclude that cohabiting fathers might feel their role substantially different from that of married fathers, with implications on their parental behaviour. For example, some authors suggest that, where the cohabitation is less "marriage like", cohabiting couples are a self-selected group aiming to breaking the traditional gendered division of family labour, including that of childcare (Ono and Yeilding 2009). In addition, Italy is a particularly interesting context for investigation also due to its gender system, which is characterized by a low level of involvement of fathers in childcare (Smith Koslowski 2008; Tanturri 2012; Neilson and Stanfors 2014). Typically, Italian mothers carry the main responsibility for these tasks. In fact, the last few decades have shown a progressive reduction in the gender imbalance in childcare between parents. However, these changes have not evenly affected all types of childcare and the mothers continue to carry the main responsibility in daily basic care (Istat 2016). Therefore, this study offers an opportunity to examine the differences in tasks characterized by a persistent gender gap for cohabiters and married fathers living in a context where cohabitation is not yet regarded as an equivalent of, or as a substitute for, marriage.

The remainder of this paper is organized as follows. The next section presents an overview of the main findings from the literature on the differences in the involvement with children between married and cohabiting fathers as well as some considerations on the peculiarity of this work. Then the data (surveys and sample characteristics) and the analysis plan (multivariate regression models and covariates) are illustrated. Some descriptive analyses of the fathers' involvement according to the type of couple are presented in the subsequent section. Next, we report the results of multivariate analyses, firstly considering an overall measure of fathers' involvement in childcare, and then distinguishing between the different specific care activities. The concluding section discusses the results. 


\section{Background}

The existing literature highlights two possible mechanisms that explore how the father's marital status could influence his involvement in childcare. One main explanation of the differences in paternal involvement between married and cohabiting fathers is related to what we can call the "de-institutionalization perspective", which relates to the concept of the "incomplete institutionalization" of cohabiting couples explored by some authors (see, for example, Baxter 2005 and Kuperberg 2012). According to this theory, the legal bond and public commitment of marriage (the "enforceable trust", see Cherlin 2004) define the roles of the individuals as parents and spouses, thus establishing, in particular, a joint investment in children by both partners (Townsend 2002); at the opposite, non-marital unions lack institutionalization (Nock 1995), which may imply ambiguity in terms of the father's parental role. Thus, married fathers would be characterized by a greater investment (both in terms of material resources and childcare) in their children than unmarried fathers, given the stronger institutional structure of marriage as opposed to cohabitation (Hofferth and Anderson 2003; Anderson et al. 2007; Berger et al. 2008). Alternatively, some authors suggest that cohabiting fathers might be more highly involved in their children's care than married fathers are because they are motivated to demonstrate their commitment to their child and to their partner (Cabrera et al. 2011; Perry et al. 2012). In this sense, the less institutional condition of unwed resident fathers could push them to represent themselves well as potential marriage partners (the "commitment perspective").

However, it could be the case that the potential differences between married and cohabiting fathers regarding paternal involvement are mediated by other factors depending on selection. In other words, it is not the marital status in itself that leads to differing childcare involvement across types of couples, but rather unmarried couples (and fathers) differ in a variety of ways from their married counterparts, and it is these factors that influence the father's investment in childcare. Firstly, cohabiters could be a selected group as regard values and attitudes; in particular, they might have less conventional expectations regarding the care of children. Cohabiters are assumed to be less likely to adhere to traditional views of the family than married individuals are and, in turn, could be more prone to a more egalitarian gendered division of domestic labour (see, for example, Liefbroer and Dourleijn 2006). This may imply that a greater investment in childcare from cohabiting fathers exists, through a greater willingness to share with their partners activities traditionally assigned to the mothers. Secondly, demographic studies have indicated that cohabiting couples can be characterized by distinct features that set them apart from married ones (Smock and Manning 2004; Kalmijn 2007) and that are connected with the fathers' involvement in childcare through several conceptual frameworks such as the household production model and sociological theories regarding time availability and relative resources (see the discussion in Kalenkoski et al. 2007). For example, cohabitation has been related to a greater participation in paid work by women (Kalmijn 2007), which is clearly positively connected with the fathers' involvement in childcare. Another factor explaining the differing involvement in childcare between cohabiting and married fathers may be their educational level, since caring for offspring is particularly valued among more educated fathers (Sayer et al. 2004; González et al. 2010), who are, in turn, more aware of the long-term consequences of care in terms of the child's development and well-being. Thus, in examining 
the difference in childcare investment between married and cohabiting fathers, it is important to control for a wide range of factors that may be associated with selection into cohabitation. Controlling for these factors should remove the cohabiting-married fathers' involvement differential.

Empirical research on this topic does not seem to clearly support one mechanism over the other. Some authors found, indeed, that, after controlling for potential selection, married fathers have a higher commitment in caregiving for their children than cohabiting ones do (Landale and Oropesa 2001; Hofferth 2006), thus confirming the "de-institutionalization perspective"; other studies showed a greater involvement among cohabiting fathers than married ones in their children's lives, also when controlling for potential selection (Cabrera et al. 2011; Hohmann-Marriot 2011). Finally, some empirical research found no evidence that cohabiting and married fathers allocated different amounts of time to childcare when controlling for the couple's and paternal characteristics (Kalenkoski et al. 2007; Gibson-Davis 2008; Pailhé et al. 2018).

In fact, the existing literature suggests even the existence of a possible interaction between fathers' behaviour in terms of their marital status and the context in which they live. The potential differences in the involvement with children between married and cohabiting fathers might depend, indeed, on the degree of diffusion and on the social acceptance of cohabitating couples. If cohabitation is deemed relatively little socially accepted, such as in Italy, cohabiting fathers might be more motivated to legitimate their union, in turn demonstrating a higher commitment to their child. In addition, the selection might also depend on the context, as suggested by some authors (Ono and Yeilding 2009; Bianchi et al. 2014). In those countries where cohabitation is less widespread and less "marriage-like" (as is the case in Italy), cohabiters may be more selected than what happens in other contexts, where cohabitations and marriages are culturally and legally perceived as similar unions. The few studies carried out on the time allocation to market and non-market work for Italian fathers seem to principally support this last hypothesis. Pailhé et al. (2018) found that when controlling for several social and demographic characteristics, cohabiting Italian fathers do not show significant differences in childcare with respect to their married counterparts. Similarly, Bianchi et al. (2014) showed that, once controls are introduced, most of the differences in childcare between cohabitating and married fathers disappear: the positive coefficient corresponding to cohabitation is still significant but its value is very small.

But, concerning the fathers' involvement in childcare according to their marital status, what happens if, instead of all childcare, only the daily basic activities that are often left to the mothers (Sayer et al. 2004; Kotila et al. 2013) are examined? The kind of childcare we are interested in is constituted of an easily definable group of tasks: feeding, putting the child to sleep, dressing the child, bathing it and changing nappies. In Italy, this kind of childcare displays the highest (72.6\%) gender asymmetry index ${ }^{4}$ within the couple with respect to the other types of childcare (Istat 2016); among these, some acts (bathing and changing nappies) are considered even more "maternal" than others given the personal nature of this type of care. Thus, we perform our analyses both for basic childcare as a whole and for some specific acts of care selected for their different level of primary care. 
In addition, in comparison to previous studies, we also account for the heterogeneity of the married couples, distinguishing between fathers who marry directly and those with pre-marital cohabitation. This distinction may be relevant: in both the hypotheses of the de-institutionalization and the commitment perspectives, fathers with pre-marital cohabitation should be more similar to those who directly married than to cohabiters; at the opposite, in the case of the self-selection of cohabiters for structural characteristics and values, a level of involvement in childcare more similar to cohabiters should be observed.

\section{Data}

The data comes from the pooling of two cross-sectional rounds of the survey "Family and Social Subjects" conducted in Italy by the Italian Statistical Institute (ISTAT) in 2003 and in 2009. Each round of the survey is based on a representative sample at the national level of about 20,000 households.

Besides socio-demographic information on each household member and on the household as a whole, detailed data on current and past marital and non-marital unions was available. In the light of this data, we can distinguish not only between unmarried and married couples but also between whether or not the marital couples started their formal union by entering directly into marriage or following a period of pre-marital cohabitation. In addition, for each baby aged 0-3 living with both parents, the father's involvement in a selection of childcare activities was investigated. The father's participation in each of five daily basic activities-feeding, putting the child to sleep, clothing, bathing, and changing its nappies-was measured on a point scale ranging from 1 (every day) to 6 (never).

Thus, we have information on the fathers' involvement in childcare activities for 3093 babies living with both parents (1655 in 2003 and 1438 in 2009) $)^{5}$ : most (2361 corresponding to $76.3 \%$ ) are children of couples who have married directly, 14.7\% (456 observations) are children of married couples with pre-marital cohabitation and 8.9\% (276 observations) are children whose parents are unwed. Table 1 presents the distributions of these three groups of children according to some relevant socio-demographic characteristics. Broadly speaking, we distinguish between five separate areas of interest for our analysis: the child's characteristics (gender, age and whether or not the child is an only child), the parents' characteristics (age, educational attainment and labour force participation), the couple's characteristics (union duration), the family arrangement and resources (formal or informal childcare and economic status) and the historical and geographical context (time and area of residence). The children-who are equally distributed in terms of sex and age into the three groups defined by the typology of couple of their parents-are often cared for by grandparents. Their parents, who on average show a relatively high union duration (almost 9 years) and a medium level of education, present a relatively high percentage of non-employed mothers. Finally, one out of three of children live in a family whose economic resources are perceived as inadequate. As expected, however, several socio-demographic characteristics are significantly associated with different types of couples. ${ }^{6}$ Direct marriages have a significantly longer union duration, and most probably in relation to this longer union, significantly higher percentages of direct marriage unions have two or more children in comparison with the 
Table 1 Sample characteristics (percentages or means) according to the type of couple

\begin{tabular}{|c|c|c|c|c|}
\hline & Direct marriage & $\begin{array}{l}\text { Marriage with } \\
\text { pre-marital } \\
\text { cohabitation }\end{array}$ & Cohabitation & Total \\
\hline \multicolumn{5}{|l|}{ Children in the household } \\
\hline One child & 38.0 & 42.8 & 52.5 & 40.0 \\
\hline Two or more children & 62.0 & 57.2 & 47.5 & 60.0 \\
\hline \multicolumn{5}{|l|}{ Age of the child } \\
\hline 0 & 22.4 & 24.3 & 26.5 & 23.1 \\
\hline 1 & 24.8 & 24.6 & 30.4 & 25.3 \\
\hline 2 & 26.5 & 26.5 & 24.3 & 26.3 \\
\hline 3 & 26.3 & 24.6 & 18.8 & 25.3 \\
\hline \multicolumn{5}{|l|}{ Gender of the child } \\
\hline Female & 46.8 & 47.4 & 51.8 & 47.4 \\
\hline Male & 53.2 & 52.6 & 48.2 & 52.6 \\
\hline Duration of the union in years (mean) $)^{* * *}$ & 9.13 & 8.61 & 5.59 & 8.74 \\
\hline \multicolumn{5}{|l|}{ Highest educational level of parents } \\
\hline High & 22.2 & 30.9 & 21.0 & 23.4 \\
\hline Medium & 53.2 & 46.1 & 50.7 & 52.0 \\
\hline Low & 24.6 & 23.0 & 28.3 & 24.6 \\
\hline \multicolumn{5}{|l|}{ Parental employment } \\
\hline Employed father and non-employed mother & 46.1 & 37.5 & 35.9 & 43.9 \\
\hline Employed father, full-time employed mother & 24.1 & 28.3 & 31.5 & 25.4 \\
\hline Employed father, part-time employed mother & 22.7 & 27.2 & 25.0 & 23.6 \\
\hline Other & 7.1 & 7.0 & 7.6 & 7.1 \\
\hline Father's age (mean) & 36.81 & 36.61 & 36.17 & 33.21 \\
\hline \multicolumn{5}{|l|}{ Grandparents involved in childcare } \\
\hline Yes & 59.7 & 58.1 & 59.8 & 59.5 \\
\hline No & 40.3 & 41.9 & 40.2 & 40.5 \\
\hline \multicolumn{5}{|l|}{ Childcare by a babysitter } \\
\hline Yes & 6.2 & 8.6 & 6.5 & 6.6 \\
\hline No & 93.8 & 91.4 & 93.5 & 93.4 \\
\hline \multicolumn{5}{|l|}{ Child goes to crèche } \\
\hline Yes & 32.1 & 36.6 & 34.4 & 32.9 \\
\hline No & 67.9 & 63.4 & 65.6 & 67.1 \\
\hline \multicolumn{5}{|l|}{ Household economic resources** } \\
\hline Sufficient & 69.1 & 66.7 & 62.3 & 68.1 \\
\hline Poor or insufficient & 30.9 & 33.3 & 37.7 & 31.9 \\
\hline \multicolumn{5}{|l|}{ Area of residence ${ }^{* * *}$} \\
\hline North & 36.6 & 53.3 & 60.1 & 41.2 \\
\hline Centre & 17.6 & 22.2 & 15.6 & 18.1 \\
\hline South & 45.8 & 24.5 & 24.3 & 41.7 \\
\hline \multicolumn{5}{|l|}{ Year of the survey } \\
\hline 2003 & 56.8 & 45.4 & 39.1 & 53.5 \\
\hline 2009 & 43.2 & 54.6 & 60.9 & 46.5 \\
\hline $\mathrm{N}$ & 2361 & 456 & 276 & 3093 \\
\hline
\end{tabular}

$p$ values for the significance of the differences across the different types of couple (chi-square test and ANOVA-for father's age and duration of the union): ${ }^{* * *}=p<0.01 ;{ }^{* *}=p<0.05 ;{ }^{*}=p<0.10$ 
other types of couple. Direct marriages are also characterized by a significantly higher percentage of the traditional male breadwinner models and are more common in the South of the country. In opposition, cohabiting couples have shorter unions and are characterized by a higher percentage of only-child households. More than half of the children in cohabiting couples have both parents employed, even if the household economic resources are significantly worse than those of the children living in other types of couples and their parents are less educated. Cohabiting couples, as expected, are concentrated in the North of the country. Marriages with a pre-marital cohabitation seem to be in an intermediate position, but with higher educated partners.

\section{Analysis plan}

We first describe the father's involvement in the childcare according to the type of union (cohabitation, direct marriage, marriage with pre-marital cohabitation). We distinguish between specific daily basic care tasks (feeding, putting the child to sleep, changing nappies, dressing the child, bathing the child) and daily basic childcare as a whole. Since in the survey the level of the fathers' involvement in specific activities is measured with an ordinal scale ranging from 1 (every day) to 6 (never), in order to have a more concise description of paternal involvement, four categories are distinguished for each activity: every day (1), not every day but several times a week (2), one time a week or two or three times a month (3-4), and less frequently or never (5-6). Instead, the fathers' involvement as a whole is analysed with a synthetic measure which distinguishes fathers with: (a) very high participation in childcare (who performed at least two activities every day and at least one of the others several times a week or every day); (b) high involvement (those who performed one activity every day and at least one of the others several times a week or who performed two activities every day); (c) medium involvement (those who performed no activity every day but with at least two activities performed several times a week); and lastly, (d) low involvement (those with less strong participation, that is those who fall into the remaining types of involvement). Preliminary analyses showed that the usage of these four categories was a robust choice even when compared with different alternative specifications.

We then turn to multivariate estimates aiming to assessing whether involvement in childcare differs for those who are cohabiting versus those who are married (distinguishing between direct marriage and marriage post-cohabitation). Ordinal logistic regression models are used to estimate the effects of the couple's typology on the specific childcare activities performed by the fathers. An ordinal logistic regression model is simply an extension of the logistic regression model used for a dichotomous response variable allowing for three or more ordered response categories which are separated by a series of thresholds (Agresti 2010). It is based on the proportional odds assumption, which, in fact, our models fail to meet; however, we opted to keep an ordinal measure of the father's involvement in the different childcare activities, since there were no substantial differences in the estimates when the dependent variable was recoded as a dichotomous. Ordinal logistic regression models are used even to assess the associations between the type of union and childcare as a whole. In fact, the choice of an ordinal logistic model for this variable could be considered questionable but this strategy has been found to be robust to alternative model specification (for example, a multinomial model has given similar results). 
For all these models, we consider as background covariates the socio-demographic characteristics of the child, the couple, the parents, the family, and the context reported in Table 1.

The child's characteristics defined by gender, age (in years), and the presence of other children in the household are taken into account. Some research has, indeed, indicated that fathers are more involved when their child is a boy rather than when the child is a girl (Lundberg et al. 2007), with younger children more than with older ones (see the review by Monna and Gauthier 2008), and with an only child, since when there are more children in the household, fathers may have less time available for any single child (Sullivan et al. 2014).

The union's duration (expressed in terms of the number of years the couple has lived together) is employed for as a measure of the stability of the relationship, but also as a proxy of the partners' family orientations. Both these interpretations suggest a negative association between duration and the father's involvement: on the one hand, a longer union duration may select couples with more conservative values regarding gender roles, values which, in turn, designate the bulk of the childcare for young children as a task for mothers. On the other hand, according to the uncertainty theory, the longer the relationship lasts, the more secure the couples become in a more specialized division of labour in the home (Stratton 2004).

In regard to the characteristics of the parents, we consider the highest educational level of at least one parent (high, medium, low), the employment status of both parents (this variable combines the status of the two partners distinguishing, for mothers, whether their job is full or part time), and the father's age (under 35, 35-39, over 39). Education may have an impact on a father's involvement in childcare, as more highly educated parents tend to have more supportive co-parenting behaviours (Yeung et al. 2001; Gracia 2014). In regard to employment status, being employed reduces involvement in childcare (Hohmann-Marriot 2011). This means that, if the mother is employed, the father's participation in childcare increases and, in opposition, the father's employment decreases his childcare. The mother's and father's ages usually correlate, but in the models we controlled for the father's age at the interview (for the role of paternal age, see Meggiolaro and Ongaro 2013 and the review by Monna and Gauthier 2008). In general, these variables are also a proxy for unobserved characteristics connected with individual orientations, cultural values and life perspectives, and thus they allow us to control, at least indirectly, for the selection of the different types of couples.

A subjective measure of household economic conditions (sufficient or poor) and the childcare strategies of families (whether grandparents are involved in childcare, whether the child is cared for by a babysitter and whether the child goes to the crèche) are covariates which represent the familial economic and informal resources (which may influence the father's involvement, especially in terms of daily basic care).

Finally, the area of residence (North, Centre, South) and the year of the survey (2003 or 2009) are also controlled for as proxies for contextual, cultural and institutional differences which can influence the father's behaviour.

All these covariates were used in multivariate models to estimate the effect of the type of union on both the fathers' daily basic childcare as a whole and the specific activities performed by fathers. A series of five models were considered in each analysis to better evaluate the potential indirect role of some covariates: the first model includes 
only the type of couple as a predictor, models 2 and 3 add other characteristics of the family (characteristics of the child and union duration, respectively), model 4 also takes into account the parents' characteristics and lastly, model 5 adds all the other controls mentioned previously. ${ }^{7}$

\section{Describing the fathers' childcare involvement according to the type of couple}

The graphs reported in Fig. 1 show different patterns for the fathers' involvement in the various childcare activities according to the type of couple. In general, a stronger participation is found in activities such as feeding and putting the child to sleep; these tasks are performed by around $40 \%$ of fathers several times a week, by about $30 \%$ of them every day. Another activity with fairly high levels of father's involvement is dressing the child: at least $20 \%$ of fathers dress their baby every day. The other tasks, bathing and changing the nappies, which are care tasks of a personal and physical nature, are performed less frequently (more than $30 \%$ of fathers almost never participate in these activities). In regard to the type of couple, higher percentages of fathers performing childcare activities every day, even the less common activities such as bathing and changing nappies, are observed among fathers who cohabit, followed by those who married following pre-marital cohabitation. Conversely, a higher proportion of fathers with low levels of involvement are observed among fathers who married directly, even if the differences are not evident in the more common activities such as feeding and putting the baby to sleep. In fact, the chi-square test shows that the differences are statistically significant only for dressing the child and changing nappies.
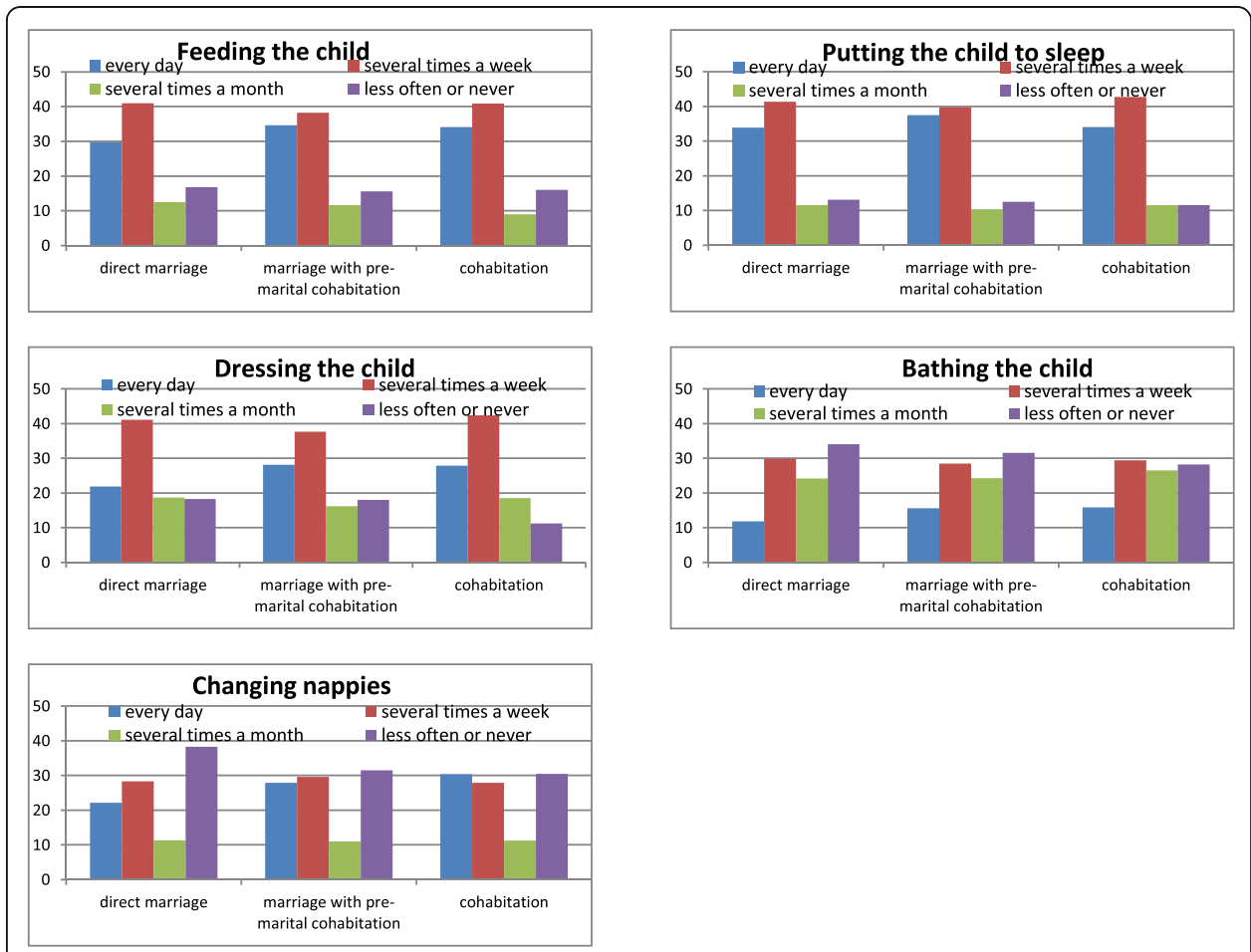

Fig. 1 Fathers' involvement in daily childcare tasks according to the type of couple 
Overall, almost half of the fathers have at least high levels of involvement in childcare (29.7\% have very high involvement and $16.7 \%$ have high involvement); $30.8 \%$ present a medium involvement and $22.8 \%$ show a low level of involvement. The percentages of fathers in these categories according to the types of couple are reported in Fig. 2.

The proportion of fathers with very high involvement is higher among fathers who married following a pre-marital cohabitation and among unmarried fathers than among those who married directly; the opposite is true for medium and low involvement. In particular, the percentage of fathers with low involvement is lower among cohabiting fathers. ${ }^{8}$

\section{Modelling the fathers' involvement}

Clearly, these figures represent marginal distributions and there may be many compositional effects producing these results. Thus, multivariate models have to be used.

\section{Modelling the father's involvement in daily basic childcare}

Table 2 shows the results of a series of ordinal logistic models that explore the determinants of the father's involvement in the childcare as a whole (very high, high, medium, low). The models predict the probability of being in a higher involvement category rather than in a lower one. For example, in model 1, the odds ratio of 1.3 (=exp 0.26) tells us that cohabiting fathers have an odds of being in a higher involvement category rather than a lower one that is 1.3 times that of directly married fathers.

Model 1 shows that fathers with experience of cohabitation (current or pre-marital) are more likely to have a very high involvement levels in childcare than directly married fathers are. These effects, however, for cohabiting fathers, rapidly disappear when controlling for the child's characteristics (model 2) and for the union's duration (model 3). Instead, the differences between directly married fathers and those who entered marriage following pre-marital cohabitation remain when controlling for these covariates (model 3), significantly decrease when the characteristics of fathers and mothers are taken into account (model 4) and completely disappear when all other controls are considered (model 5).

In conclusion, there is no evidence that the experience of cohabitation matters for the level of the father's involvement in daily basic childcare: the effect of the type of

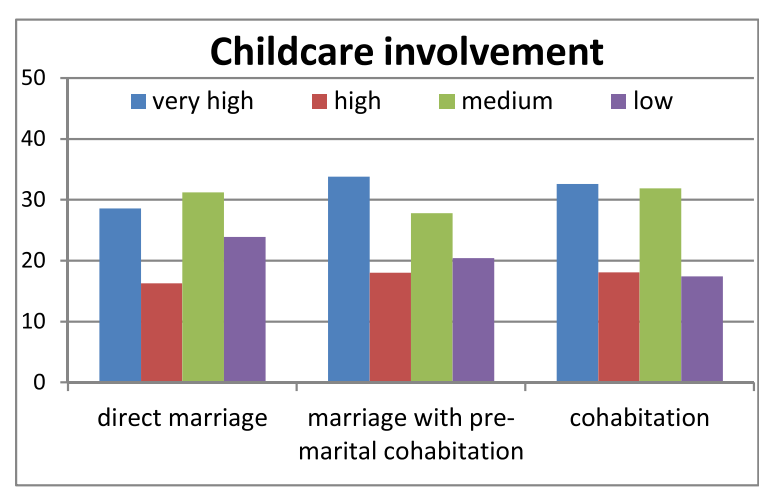

Fig. 2 Fathers' involvement in daily basic childcare by the different types of couple 
Table 2 Ordinal logistic models for fathers' involvement in daily basic childcare as a whole- $\beta$ coefficients (coefficients predicting higher involvement of fathers-3093 observations)

\begin{tabular}{|c|c|c|c|c|c|}
\hline & Model 1 & Model 2 & Model 3 & Model 4 & Model 5 \\
\hline \multicolumn{6}{|c|}{ Type of union (ref: marriage without pre-marital cohabitation) } \\
\hline Marriage with pre-marital cohabitation & $0.25^{* * *}$ & $0.24^{* * *}$ & $0.23^{* *}$ & $0.19^{*}$ & 0.13 \\
\hline Cohabitation & $0.26^{* *}$ & $0.21^{*}$ & 0.16 & 0.14 & 0.08 \\
\hline \multicolumn{6}{|l|}{ Only child (ref: no) } \\
\hline Yes & & $0.16^{* *}$ & 0.09 & 0.02 & 0.02 \\
\hline \multicolumn{6}{|l|}{ Child's age (ref: 0 ) } \\
\hline 1 & & 0.01 & 0.01 & 0.05 & 0.04 \\
\hline 2 & & 0.07 & 0.06 & 0.09 & 0.07 \\
\hline 3 & & $-0.34^{* * *}$ & $-0.36^{* * *}$ & $-0.34^{* * *}$ & $-0.41^{* * *}$ \\
\hline \multicolumn{6}{|l|}{ Child's gender (ref: $F$ ) } \\
\hline Male & & 0.10 & 0.11 & $0.12^{*}$ & $0.12^{*}$ \\
\hline Union duration & & & $-0.02^{* * *}$ & $-0.02^{* *}$ & $-0.02^{* *}$ \\
\hline \multicolumn{6}{|l|}{ Educational status of parents (ref: low) } \\
\hline High & & & & $0.40^{* * *}$ & $0.40^{* * *}$ \\
\hline Medium & & & & $0.22^{* * *}$ & $0.19^{* *}$ \\
\hline \multicolumn{6}{|c|}{ Parental employment (ref: empl. father and non-empl. mother) } \\
\hline Empl. father, full-time empl. mother & & & & $0.50^{* * *}$ & $0.44^{* * *}$ \\
\hline Empl. father, part-time empl. mother & & & & $0.43^{* * *}$ & $0.35^{* * *}$ \\
\hline Other & & & & $0.32^{* *}$ & $0.37^{* * *}$ \\
\hline \multicolumn{6}{|l|}{ Father's age (ref: under 35) } \\
\hline $35-39$ & & & & -0.02 & -0.03 \\
\hline$>40$ & & & & 0.01 & 0.01 \\
\hline \multicolumn{6}{|l|}{ Grandparents involved in childcare (ref: No) } \\
\hline Yes & & & & & 0.04 \\
\hline \multicolumn{6}{|l|}{ Childcare by a babysitter (ref: No) } \\
\hline Yes & & & & & -0.10 \\
\hline \multicolumn{6}{|l|}{ Crechè (ref: No) } \\
\hline Yes & & & & & 0.08 \\
\hline \multicolumn{6}{|l|}{ Household economic resources (ref: sufficient) } \\
\hline Insufficient & & & & & -0.01 \\
\hline \multicolumn{6}{|l|}{ Area of residence (ref: South) } \\
\hline Centre & & & & & $0.24^{* *}$ \\
\hline North & & & & & $0.26^{* * *}$ \\
\hline \multicolumn{6}{|l|}{ Year of the survey (ref: 2003) } \\
\hline 2009 & & & & & -0.01 \\
\hline
\end{tabular}

couple is, indeed, cancelled out after controlling for the characteristics of the couple and of the parents associated with the different types of union. In particular, fathers who entered into marriage following pre-marital cohabitation are selected through theirs and their partner's characteristics, defined mainly by education and employment status, which, as noted above, can also be considered as proxies for unobserved characteristics connected with orientations and values. The feature that selects for childcare involvement of cohabiting fathers is connected with the child's characteristics and the 
union's duration. The role played by the duration of the union may have different interpretations. Again, union duration may be connected with unobserved characteristics such as religiosity or perspectives on life, which could lead couples assuming more or less traditional gender roles. Alternatively, more specialized roles may emerge after the end of a first phase of "enthusiastic" activity-sharing associated with the first years of a partnership or, more probably, to rational choices that suggest the partners to specialize in family work only in view of longer-lasting partnerships.

\section{Modelling the father's involvement in different childcare activities}

Three ordinal logistic regression models are used to estimate the effect of the type of couple on the specific childcare activities provided by the fathers. The models (Table 3) refer to only three activities ${ }^{9}$ chosen for the fact that they can be more or less traditionally attributed to the mothers: putting the baby to sleep (with a low connotation of primary care, thus less traditionally attributed to mothers, and which Fig. 1 showed to be the most common tasks performed by fathers), dressing the child (intermediate level) and changing nappies (a high level of basic care and thus traditionally attributed to mothers). The models predict the probability of being in a lower involvement category rather than in a higher one. For example, in model 1 of part $B$ of Table 3, the odds ratio of 0.7 (=exp - 0.35) tells us that cohabiting fathers have an odds of being in a lower involvement category rather than in a higher one that is $30 \%$ lower than directly married fathers have.

In regard to putting the child to sleep (analyses referring to feeding reported similar results), part A of Table 3 shows that already in model 1 there are no differences across fathers for the different types of couple. Part B of Table 3 shows that fathers with cohabitation experience have higher participation levels in terms of dressing their babies in comparison to directly married fathers, but that those differences disappear when taking into account the parents' characteristics (model 4) for married fathers following pre-marital cohabitation and when accounting for the union's duration (model 3), and geographical context (model 5) for cohabiting fathers. Part $C$ of Table 3 regards the less common activity of changing nappies (analyses not reported here and referred to bathing the child also produced similar results): the higher involvement for married fathers following pre-marital cohabitation disappears when taking into account the family and parents' characteristics (model 4) and some other controls, such as the geographical context and the household's economic resources (model 5). Instead, the higher commitment for cohabiting fathers disappears once the union duration (model 3), child's (models 1 and 2) and parents' characteristics (model 4) are controlled for.

\section{Concluding remarks}

This study offers new information regarding Italian father's involvement with very young children: it examines whether or not married and cohabiting fathers are differently involved in the daily basic childcare that is traditionally attributed to the mothers and, if so, whether the differences are due to the type of couple per se or to specific characteristics of the family. Daily basic childcare represents a partial dimension of the multiple components characterizing parental involvement. However, since it can be of primary importance both for improving father-child relationships and for easing the 
Table 3 Ordinal logistic models for fathers' involvement in some childcare activities - $\beta$ coefficients (coefficients predicting lower involvement of fathers - 3093 observations).

\begin{tabular}{|c|c|c|c|c|c|}
\hline & Model 1 & Model 2 & Model 3 & Model 4 & Model 5 \\
\hline \multicolumn{6}{|l|}{ A. Putting the child to sleep } \\
\hline \multicolumn{6}{|c|}{ Type of union (ref: marriage without pre-marital cohabitation) } \\
\hline Marriage with pre-marital cohabitation & -0.13 & -0.12 & -0.11 & -0.09 & -0.09 \\
\hline Cohabitation & -0.05 & -0.03 & 0.03 & 0.02 & 0.01 \\
\hline \multicolumn{6}{|l|}{ Only child (ref: no) } \\
\hline Yes & & -0.03 & 0.04 & 0.06 & 0.06 \\
\hline \multicolumn{6}{|l|}{ Child's age (ref: 0 ) } \\
\hline 1 & & 0.03 & 0.03 & -0.01 & -0.01 \\
\hline 2 & & -0.01 & -0.00 & -0.02 & -0.01 \\
\hline 3 & & $0.31^{* * *}$ & $0.32^{* * *}$ & $0.31^{* * *}$ & $0.39 * * *$ \\
\hline \multicolumn{6}{|l|}{ Child's gender (ref: $F$ ) } \\
\hline Male & & -0.10 & -0.11 & -0.10 & -0.10 \\
\hline Union duration & & & $0.02^{* * *}$ & $0.01^{* *}$ & $0.01^{*}$ \\
\hline \multicolumn{6}{|l|}{ Educational status of parents (ref: low) } \\
\hline High & & & & $-0.40^{* * *}$ & $-0.40^{* * *}$ \\
\hline Medium & & & & $-0.25^{* * *}$ & $-0.23^{* * *}$ \\
\hline \multicolumn{6}{|c|}{ Parental employment (ref: empl. father and non-empl. mother) } \\
\hline Empl. father, full-time empl. mother & & & & $-0.19^{* *}$ & $-0.18^{* *}$ \\
\hline Empl. father, part-time empl. mother & & & & $-0.21^{* *}$ & $-0.20^{* *}$ \\
\hline Other & & & & $-0.42^{* * *}$ & $-0.44^{* * *}$ \\
\hline \multicolumn{6}{|l|}{ Father's age (ref: under 35) } \\
\hline $35-39$ & & & & -0.05 & -0.05 \\
\hline$>40$ & & & & 0.03 & 0.02 \\
\hline \multicolumn{6}{|l|}{ Grandparents involved in childcare (ref: No) } \\
\hline Yes & & & & & -0.03 \\
\hline \multicolumn{6}{|l|}{ Childcare by a babysitter (ref: No) } \\
\hline Yes & & & & & $0.30^{*}$ \\
\hline \multicolumn{6}{|l|}{ Crechè (ref: No) } \\
\hline Yes & & & & & -0.10 \\
\hline \multicolumn{6}{|l|}{ Household economic resources (ref: sufficient) } \\
\hline Insufficient & & & & & 0.08 \\
\hline \multicolumn{6}{|l|}{ Area of residence (ref: South) } \\
\hline Centre & & & & & -0.01 \\
\hline North & & & & & 0.04 \\
\hline \multicolumn{6}{|l|}{ Year of the survey (ref: 2003) } \\
\hline 2009 & & & & & -0.01 \\
\hline \multicolumn{6}{|c|}{ B. Dressing the child } \\
\hline \multicolumn{6}{|c|}{ Type of union (ref: marriage without pre-marital cohabitation) } \\
\hline Marriage with pre-marital cohabitation & $-0.20^{* *}$ & $-0.19^{* *}$ & $-0.15^{* *}$ & -0.14 & -0.08 \\
\hline Cohabitation & $-0.35^{* * *}$ & $-0.32^{* * *}$ & $-0.25^{* *}$ & $-0.24^{* *}$ & -0.18 \\
\hline \multicolumn{6}{|l|}{ Only child (ref: no) } \\
\hline Yes & & $-0.19^{* * *}$ & -0.11 & -0.04 & -0.06 \\
\hline
\end{tabular}


Table 3 Ordinal logistic models for fathers' involvement in some childcare activities- $\beta$ coefficients (coefficients predicting lower involvement of fathers - 3093 observations). (Continued)

\begin{tabular}{|c|c|c|c|c|c|}
\hline & Model 1 & Model 2 & Model 3 & Model 4 & Model 5 \\
\hline \multicolumn{6}{|l|}{ Educational status of parents (ref: low) } \\
\hline High & & & & $-0.46^{* * *}$ & $-0.51^{* * *}$ \\
\hline Medium & & & & $-0.25^{* * *}$ & $-0.25^{* * *}$ \\
\hline \multicolumn{6}{|c|}{ Parental employment (ref: empl. father and non-empl. mother) } \\
\hline Empl. father, full-time empl. mother & & & & $-0.63^{* * *}$ & $-0.58^{* * *}$ \\
\hline Empl. father, part-time empl. mother & & & & $-0.45^{* * *}$ & $-0.35^{* * *}$ \\
\hline Other & & & & -0.20 & $-0.25^{*}$ \\
\hline \multicolumn{6}{|l|}{ Father's age (ref: under 35) } \\
\hline $35-39$ & & & & -0.05 & -0.04 \\
\hline$>40$ & & & & -0.12 & -0.14 \\
\hline \multicolumn{6}{|l|}{ Grandparents involved in childcare (ref: No) } \\
\hline Yes & & & & & -0.09 \\
\hline \multicolumn{6}{|l|}{ Childcare by a babysitter (ref: No) } \\
\hline Yes & & & & & 0.12 \\
\hline \multicolumn{6}{|l|}{ Crechè (ref: No) } \\
\hline Yes & & & & & 0.02 \\
\hline \multicolumn{6}{|c|}{ Household economic resources (ref: sufficient) } \\
\hline Insufficient & & & & & $-0.15^{*}$ \\
\hline \multicolumn{6}{|l|}{ Area of residence (ref: South) } \\
\hline Centre & & & & & $-0.39 * * *$ \\
\hline North & & & & & $-0.39^{* * *}$ \\
\hline \multicolumn{6}{|l|}{ Year of the survey (ref: 2003) } \\
\hline 2009 & & & & & 0.08 \\
\hline
\end{tabular}

mother's workload, this topic is worthy of examination: perhaps this is especially worthy of consideration in a country such as Italy, where non-marital unions have only recently started spreading and where fathers are traditionally minimally involved in childcare duties. Daily basic childcare was considered both as a whole and via some specific activities that were selected for their different level of primary care levels. In addition, potential differences among married fathers were also examined, distinguishing between those who entered directly into marriage and those experiencing pre-marital cohabitation.

The results show that cohabiting fathers are significantly more involved than married ones are in the childcare as a whole (and among the latter group, those who experienced pre-marital cohabitation are more involved than the others). However, once the background covariates are controlled for, the differences across the types of couples disappear. This confirms what has been found in previous studies on Italy on all childcare for dependent children even for basic childcare for youngest offspring: potential differences between married and unmarried couples with respect to the father's involvement depend on the fact that they are selected for specific characteristics, which are differently associated with paternal involvement in childcare (Bianchi et al. 2014; Pailhé et al. 2018). 
With respect to previous studies, however, this study sheds further light on how the selection process influences the fathers' behaviour regarding childcare as a whole. Obviously, given the cross-sectional structure of our data, we cannot fully address the selection issue but at least some points can be highlighted. Firstly, the higher levels of basic childcare of cohabiting fathers seem to depend on both the age of the child (early infancy) and on the specific conditions of the couple (first child and a short union duration), which, in turn, are associated with higher involvement by the fathers. In particular, it seems that a significant aspect of the higher involvement of cohabiting fathers is "explained" by the fact that non-marital unions are, on average, shorter than marriages are (as shown in Table 1). Interestingly, this result is consistent with Stratton's (2004) findings in terms of the couple's specialization in housework. She reported a positive association between the duration of the relationship and a specialization in housework and interpreted this as an evidence of her theory about uncertainty: the longer the relationship is, the more secure the couple has become in a more specialized division of labour in the home. It could be that the theory of uncertainty holds even in the case of childcare. A second finding is that even a higher level of childcare involvement for fathers who entered marriage after a period of cohabitation depends on a selection process, but in this case, the differences are due both to some parental characteristics (the parents' education and employment status) and to the geographical context (area of residence). Higher educational levels make fathers more aware of the importance of their care for child development and well-being; similarly, couples where the mother is involved in paid work are forced into a more egalitarian gendered division of family labour. However, we cannot exclude that these structural characteristics absorb, at least partly, potential differences with respect to preferences and attitudes that make these parents more prone to breaking the traditional roles around the household division of labour. Thus, cohabiting couples who then marry may even be selected for their values and orientations.

With respect to fathers who enter directly into marriage, those who both cohabit or have experienced cohabitation show not only higher involvement in basic childcare as a whole, but also differences in the types of childcare they provide to their children. As regards the specific activities of childcare, they are more involved in activities characterized by medium (dressing their child) or high (changing nappies) connotations of primary care but, even in this case, the differences disappear after controlling for the background characteristics and these characteristics differ between cohabiting fathers and those married following cohabitation.

In summary, the results do not suggest that cohabiting fathers, even if they are living in a context such as Italy where cohabitation is less widespread and less "marriage-like" than in other countries, are more motivated to demonstrate their commitment to the child. In regard to the behaviour of married fathers following pre-marital cohabitation, their higher levels of childcare involvement could depend on the fact that they are a sub-group of cohabiting couples selected for characteristics that are associated both with higher childcare involvement and with a higher likelihood of progressing towards marriage: in this case, we may assume that the potential higher paternal involvement associated with cohabitation persists even within the marriage. It is also possible that men who move from cohabitation to marriage are more likely to perceive the institutional aspects of marriage, including those connected to the paternal role. In this case, 
the results might be attributable to residual cultural differences among the fathers that are not completely controlled for by the covariates. Unfortunately, the cross-sectional nature of our data does not allow us to further develop these suggestions. Further analyses following both the couple and the paternity carriers, as well as the individual norms and values from a longitudinal perspective, will be able to confirm these hypotheses. Anyway, this result suggests the importance of distinguishing among married couples those with a pre-marital cohabitation, at least for a country experiencing family transitions such as Italy.

\section{Endnotes}

${ }^{1}$ The activities considered in this paper are part of the engagement dimension, which is the most restrictive type of paternal involvement, and refers to the time spent in actual one-on-one interaction with the child. Accessibility refers to activities characterized by less intense degrees of interaction (for example, cooking in the kitchen while the child watches TV); responsibility "reflects the extent to which the parent takes ultimate responsibility for the child's welfare and care" (Lamb 2000, p. 31).

${ }^{2}$ https://ec.europa.eu/eurostat/web/population-demography-migration-projections/ data/main-tables

${ }^{3}$ The legal rights of cohabiting couples have been recognized and regulated only recently by Law 76/2016. The data used in this paper refers to a period when cohabitations were not legally recognized.

${ }^{4}$ The gender asymmetry index is defined as the ratio between the time dedicated to some activities by the woman and that dedicated by both partners.

${ }^{5}$ The majority of them (90\%) are babies without siblings in the same age group 0-3 (in 2003 and in 2009 they are, respectively, 1493 and 1278). Thus, the sample of children does not suffer from possible problems due to the over-representation of children belonging to the same family.

${ }^{6} \mathrm{We}$ used chi-square and ANOVA statistics to test the significance of the association between each socio-demographic characteristic and the type of couple.

${ }^{7}$ Alternative sequences of models were also tested. The results of the sequence reported here are robust to these alternatives and the contribution of the different variables resulted in the same findings with alternative sequences.

${ }^{8}$ The significance of the chi-square statistic supports these results.

${ }^{9}$ For each activity, the level of the father's involvement is measured with an ordinal scale ranging from 1 (every day) to 6 (never).

Acknowledgements

Not applicable.

Funding

The manuscript is part of a research conducted within two research projects: (a) European Union's Seventh Framework Programme [FP7/2007-2013] under grant agreement no. [320116] for the research project Families and Societies and

(b) "The Italian families between tradition and innovation. New types, new challenges and new opportunities" supported by the University of Padova in the ambit of the 2013 University Research Projects, grant number CPDA139158. 


\section{Authors' contributions}

All authors read and approved the final version of the manuscript. However, the different sections can be attributed to each author as follows: SM is responsible for the Analysis plan, Modelling the fathers' involvement, Modelling the father's involvement in daily basic childcare, Modelling the father's involvement in different childcare activities, and concluding remarks. FO is responsible for the Introduction, Background, Data, and Describing the fathers' childcare involvement according to the type of couple.

\section{Ethics approval and consent to participate}

Not applicable (data collected and diffused by the Italian Statistical Institute).

\section{Consent for publication}

Not applicable.

\section{Competing interests}

The authors declare that they have no competing interests.

\section{Publisher's Note}

Springer Nature remains neutral with regard to jurisdictional claims in published maps and institutional affiliations.

Received: 10 April 2018 Accepted: 5 December 2018

Published online: 18 January 2019

\section{References}

Agresti, A. (2010). Analysis of ordinal categorical data (2nd ed.). Hoboken: Wiley.

Aldous, J., \& Mulligan, G. (2002). Father's child care and children's behavioral problems. Journal of Family Issues, 23, 624-647.

Anderson, K. G., Kaplan, H., \& Lancaster, J. B. (2007). Confidence of paternity, divorce, and investment in children by

Albuquerque men. Evolution and Human Behavior, 28, 1-10.

Baxter, J. (2005). To marry or not to marry. Marital status and the household division of labor. Journal of Family Issues, 26, $300-321$.

Berger, L. M., Carlson, M. J., Bzostek, S. H., \& Osborne, C. (2008). Parenting practices of resident fathers: The role of marital and biological ties. Journal of Marriage and Family, 70(3), 625-639.

Bianchi, S., Lesnard, L., Nazio, T., \& Raley, S. (2014). Gender and time allocation of cohabiting and married women and men in France, Italy, and the United States. Demographic Research, 31, 183-216.

Bronte-Tinkew, J., Carrano, J., Horowitz, A., \& Kinukawa, A. (2008). Involvement among resident fathers and links to infant cognitive outcomes. Journal of Family Issues, 29(9), 1211-1244.

Cabrera, N. J., Hofferth, S. L., \& Chae, S. (2011). Patterns and predictors of father-infant engagement across race/ethnic groups. Early Childhood Research Quarterly, 26(3), 365-375.

Cherlin, A. J. (2004). The deinstutionalization of American marriage. Journal of Marriage and Family, 66, 848-861.

Gibson-Davis, C. M. (2008). Family structure effects on maternal and paternal parenting in low-income families. Journal of Marriage and Family, 70, 452-465.

González, M., Miret, P., \& Treviño, R. (2010). Just living together': Implications of cohabitation for fathers' participation in child care in Western Europe. Demographic Research, 23(16), 463-466.

Gracia, P. (2014). Fathers' child care involvement and children's age in Spain: A time use study on differences by education and mothers' employment. European Sociological Review, 30(2), 137-150.

Hofferth, S. L. (2006). Residential father family type and child well-being: Investment versus selection. Demography, 43, 53-77.

Hofferth, S. L., \& Anderson, K. G. (2003). Are all dads equal? Biology versus marriage as a basis for paternal investment. Journal of Marriage and Family, 65, 213-232.

Hohmann-Marriot, B. (2011). Coparenting and father involvement in married and unmarried coresident couples. Journal of Marriage and Family, 73, 296-309.

Istat (2016). I tempi della vita quotidiana. Statistiche Report, Istituto Nazionale di Statistica, Roma.

Kalenkoski, C., Ribar, D., \& Stratton, L. (2007). The effect of family structure on parents' child care time in the United States and the United Kingdom. Review of Economics of the Household, 5(4), 353-384.

Kalmijn, M. (2007). Explaining cross-national differences in marriage, cohabitation and divorce in Europe. Population Studies, $61(3), 243-263$.

Kasearu, K., \& Kutsar, D. (2011). Patterns behind unmarried cohabitation trends in Europe. European Societies, 13(2), $307-325$.

Kiernan, K. (2002). The state of European unions: an analysis of partnership formation and dissolution. In M. Macura \& G. Beets (Eds.), Dynamics of fertility and partnership in Europe. Insights and lessons from comparative research (Vol. 1, pp. 57-76). Geneva: United Nations.

Kotila, L. E., Schoppe-Sullivan, S. J., \& Kamp Dush, C. M. (2013). Time in parenting activities in dual-earner families at the transition to parenthood. Family Relations, 62(5), 795-807.

Kuperberg, A. (2012). Reassessing differences in work and income in cohabitation and marriage. Journal of Marriage and Family, 74, 688-707.

Lamb, M. E. (2000). The history of research of father involvement. Marriage and Family Review, 29, 23-42.

Lamb, M. E., Plek, J. H., Charnov, E. L., \& Levin, J. A. (1987). A biosocial perspective of paternal behavior and involvement. In J. B. Lancaster, J. Altman, A. S. Rossi, \& L. R. Sherrod (Eds.), Parenting across the lifespan: Biosocial Perspectives (pp. 111-142). Hawtorne: Aldine.

Landale, N. S., \& Oropesa, R. S. (2001). Father involvement in the lives of mainland Puerto Rican children: Contributions of nonresident, cohabiting and married fathers. Social Forces, 79, 945-968.

Liefbroer, A. C., \& Dourleijn, E. (2006). Unmarried cohabitation and union instability: Testing the role of diffusion using data from 16 European countries. Demography, 43(2), 203-221. 
Lundberg, S., McLanahan, S., \& Rose, E. (2007). Child gender and father involvement in fragile families. Demography, $44,79-92$.

Meggiolaro, S., \& Ongaro, F. (2013). Maternal age and parenting strategies. Genus, LXIX, 3, 1-24.

Monna, B., \& Gauthier, A. H. (2008). A review of the literature on the social and economic determinants of parental time. Journal of Family and Economic Issues, 29, 634-653.

Neilson, J., \& Stanfors, M. (2014). It's about time! Gender, parenthood and household divisions of labor under different welfare regimes. Journal of Family Issues, 35(8), 1066-1088.

Nock, S. L. (1995). A comparison of marriages and cohabiting relationships. Journal of Family Issues, 16, 53-76.

Ono, H., \& Yeilding, R. (2009). Marriage, cohabitation and chilcare: The US and Sweden. Social Indicators Research, 93, 137-140.

Pailhé, A., Solaz, A., \& Tanturri, M. L. (2018). The time cost of raising children in different fertility contexts: Evidence from France and Italy. European Journal of Population. https://doi.org/10.1007/s10680-018-9470-8.

Perry, A. R., Harmon, D. K., \& Leeper, J. (2012). Resident black fathers' involvement. A comparative analysis of married and unwed, cohabitating fathers. Journal of Family Issues, 33(6), 695-714.

Pleck, J. H. (2010). Why could father involvement benefit children? Theoretical perspectives. Applied Developmental Sciences, 11(4), 196-202.

Pleck, J. H., \& Masciadrelli, B. P. (2004). Paternal involvement in U.S. residential fathers: Levels, sources, and consequences. In M. E. Lamb (Ed.), The role of the father in child development (pp. 222-271). New York: Wiley.

Salvini, S., \& De Rose, A. (Eds.). (2011). Rapporto sulla popolazione. L'ttalia a 150 anni dall'Unità. Bologna: II Mulino.

Sayer, L. C., Bianchi, S. M., \& Robinson, J. P. (2004). Are parents investing less in children? Trends in mothers' and fathers' time with children. American Journal of Sociology, 110, 1-43.

Smith Koslowski, A. (2008). Who Cares? European fathers and the time they spend looking after their children. Saarbrücken: VDM Verlag.

Smith Leavell, A., Tamis-LeMonda, C. S., Ruble, D. N., Zosuls, K. M., \& Cabrera, N. J. (2012). African American, white and Latino father's activities with their sons and daughters in early childhood. Sex Roles, 66, 53-65.

Smock, P. J., \& Manning, W. D. (2004). Living together unmarried in the United States: Demographic perspectives and implications for family policy. Law and Policy, 26(1), 87-117.

Stratton L.S. (2004): Specialization in household activities within cohabiting versus married households. IZA Working Paper.

Sullivan, O., Billari, F. C.. \& Altintas, E. (2014). Fathers' changing contributions to child care and domestic work in very lowfertility countries: The effect of education. Journal of Family Issues, 35(8), 1048-1065.

Tanturri, M. L. (2012). How much does a child cost its parents in terms of time in an aged society? An estimate for Italy with time-use survey data. In G. De Santis (Ed.), The Family, The Market or the State? Intergenerational Support under Pressure in Ageing Societies, International Studies in Population (Vol. 10). Berlin: Springer/IUSSP.

Townsend, N. W. (2002). The package deal: Marriage, work and fatherhood in men's lives. Philadelphia: Temple University Press.

Yeung, W. J., Sandberg, J. F., Davis-Kean, P. E., \& Hofferth, S. (2001). Children's time with fathers in intact families. Journal of Marriage and Family, 63, 136-154.

\section{Submit your manuscript to a SpringerOpen ${ }^{\circ}$ journal and benefit from:}

- Convenient online submission

- Rigorous peer review

- Open access: articles freely available online

- High visibility within the field

- Retaining the copyright to your article

Submit your next manuscript at $\boldsymbol{\nabla}$ springeropen.com 